\title{
Marine-Derived Pharmaceuticals - Challenges and Opportunities
}

\author{
Ulrike Lindequist* \\ Department of Pharmaceutical Biology, Institute of Pharmacy, Ernst-Moritz-Arndt University of Greifswald, Greifswald D17489, \\ Germany
}

\begin{abstract}
Marine biosphere is the largest one of the earth and harbors an enormous number of different organisms. Living conditions differ fundamentally from those in terrestrial environment. The production of specific secondary metabolites is an important adaption mechanism of marine organisms to survive in the sea. These metabolites possess biological activities which make them interesting as possible drugs for human. The review presents sources, chemistry, production and pharmacology of FDA approved marine derived pharmaceuticals arranged according to their therapeutic indication. Four of the presently seven approved drugs are used for the treatment of cancer. Each another one is applicated for treatment of viral diseases, chronic pain and to lower triglyceride level in blood. Some other products are of interest in diagnostic and as experimental tools. Besides, this article describes challenges in drug development from marine sources, especially the supply problem.
\end{abstract}

Key Words: Marine drug development, Cytostatics, Analgetics, Antiviral, Antihyperlipidemic

\section{INTRODUCTION}

With more than $70 \%$ of the earth's surface, the oceans represent the largest habitat of the earth and a prolific resource of organisms with high biological and chemical diversity. Although most drugs are still derived from terrestrial sources, a considerable number of drugs, drug candidates and other metabolites from marine organisms have been identified in recent years. About 30,000 compounds of marine origin are known and, since 2008, more than 1,000 compounds are newly discovered each year. They are often characterized by structural novelty, complexity, and diversity (Kiuru et al., 2014; $\mathrm{Hu}$ et al., 2015). Continuous annual reviews about novel marine natural products are published in Natural Products Report by Faulkner till 2002 and then by Blunt et al. Only the last one from 2016 is cited in this review (Blunt et al., 2016).

From a historical perspective, the oldest marine product was the dye Tyrian purple extracted from marine molluscs by the Phoenicians about 1600 BC. For a long time, the marine natural products field focused on metabolites from fish and marine algae. Famous examples are marine biopolymers like agar and carrageenan, the vitamins $A$ and $D$ from fish liver oil or polyunsaturated fatty acids like eicosapentaenoic acid and docosahexaenoic acid. The real marine drug development started with the discovery of spongothymidine and spongouridine in the 1950s from the Caribbean sponge Tethya crypta (Bergmann and Feeney, 1951; Bergman and Burke, 1955; Sagar et al., 2010, Anjum et al., 2016; Newman and Cragg, 2016). Cephalosporin C, produced by the fungus Acremonium chrysogenum, isolated from Mediterranean sea water samples nearby Sardinia in the 1940s, was the starting point for the development of the antibiotic class of cephalosporins (König, 1992). Weinheimer and Spraggins published the high content of prostaglandins in the gorgonian Plexaura homomalla in 1969 (Weinheimer and Spraggins, 1969). A look at patent applications on marine natural products reveals a strong increase since middle of 1980s (Bongiorni and Pietra, 1996). Most compounds have been isolated from marine invertebrates. Meanwhile, marine microorganisms attract more and more attention (Jensen and Fenical, 2000; Schweder et al., 2005; Tarman et al., 2013).

The review gives an overview about presently approved drugs of marine origin and some other products of medicinal value. Biopolymers (polysaccharides: agar, carrageenan, alginates, antiviral sulfated polysaccharides from algae; chitin from crabs and its derivative chitosan), mussel adhesive proteins, vitamins (vitamin A and D in fish liver oils from Gadus morrhua and Hippoglossus hippoglossus), minerals (iod), UV protecting marine compounds (mycosporine acids, carotenoids, photolyase) and further marine products for cosmetics

Received Aug 11, 2016 Revised Oct 4, 2016 Accepted Oct 5, 2016 Published Online Nov 1, 2016

*Corresponding Author

E-mail: lindequi@uni-greifswald.de

Tel: +49-3834-864868, Fax: +49-3834-864885 
(antiinflammatory pseudopterosins from the coral Pseudopterogorgia elisabethae etc.) are not in the focus of this review. For actual overview about marine-derived nutraceuticals see Suleria et al. (2015), for marine-derived cosmetics and cosmeceuticals see Thomas and Kim (2013) and Martins et al. (2014).

\section{MARINE ENVIRONMENT}

The marine environment is one of the richest biospheres on earth. Living conditions in the oceans differ fundamentally from those on the earth. We find huge ranges in temperature (from $-1.5^{\circ} \mathrm{C}$ in ice sea to $350^{\circ} \mathrm{C}$ in deep hydrothermal systems), pressure (1 to over 1,000 atmospheres), light (complete darkness to extensive photic zones) and nutritional conditions (nutrient-rich till nutrient-sparse) and an enormous high number of different species. The World Register of Marine Species (2016, http://www.marinespecies.org/) counts currently about 240,000 known species. But there is a lot of confusion because there are often different names for the same species (Snelgrove, 2016). To date only a fraction of the types of organisms which live in the sea are known. In the frame of the worldwide research project Census of marine life (c2010, http://www.coml.org/) numerous new species have been detected. The highest number of species was found in the sea around Australia $(32,889)$ and Japan $(32,777)$. About $60 \%$ of marine animals belong to the invertebrates. Of the about thirty six animal phyla so far reported, around half are exclusive to the sea. It was concluded that at least $50 \%$ and potentially $>90 \%$ of marine species remain undescribed by science (Burgess, 2012; Caron et al., 2012; Snelgrove, 2016). Many marine organisms are sessile, attached to either the ocean bottom or stones, wood, living or dead animals and plants or other materials. Close associations between different groups of organisms, e.g. coral riffs or sponges, which house many types of microorganisms are very characteristic for marine life. The special conditions of living in the marine environment necessitate special mechanisms of adaption of organisms to growing in the ocean that are fundamentally different from those in land-based organisms. One important adaption mechanism is the production of biologically active secondary metabolites. Functions of such metabolites are intra- and interspecific signaling, deterrence of herbivores and predators, suppression of competing neighbors, inhibition of bacterial and fungal invasion, or protection against UV radiation. These chemicals have enormous potential to become drugs, medicinal products, experimental tools or food supplements (Lindequist and Schweder, 2001; Molinski et al., 2009; Hill and Fenical, 2010; Proksch et al., 2010; Debbab et al., 2010; Radjasa et al., 2011; Newman and Cragg, 2004, 2014, 2016).

\section{MARINE BIOPROSPECTING}

Bioprospecting for new marine products has increased significantly over the last decades. Till now, marine invertebrates have been the most important source (Radjasa et al., 2011; Leal et al., 2012; Hu et al., 2015). Across animals, the sponges (Porifera) account for almost half of new natural products since 1990, corals and jellies (Cnidaria) for 30\%, seastars and other Echinodermata, vertebrates (Chordata) and mollusk
(Mollusca) for each 5\%. Further compounds have been found in polychaetes (Annelida), moss animals (Bryozoa), flatworms (Platyhelminthes), acorn worms and relatives (Hemichordata), lamp shells (Brachiopoda) and crustaceans (Arthropoda) (Snelgrove, 2016). Several studies have demonstrated that natural products isolated from higher marine organisms like marine invertebrates are frequently of microbial origin, often bacteria or cyanobacteria. However, these microorganisms, which are for example in a symbiotic association with higher organisms, usually cannot be cultivated alone in a pure culture. Their growth depends directly on the activity of their hosts. If the cultivation of the microorganisms under axenic conditions is possible, probably only a part of their biosynthetic genes is transcribed. Many biosynthetic genes remain silent and are not expressed in vitro. The exploitation of the whole biochemical potential of these organisms is an important challenge (Faulkner et al., 2000; Schweder et al., 2005; Gross, 2009; Marmann et al., 2014; Martins et al., 2014). In this context, the exploitation of the genomic information of whole communities, the so-called metagenome analysis, gets more and more importance. It enables direct access to the genomes of uncultivable microorganisms and microbial communities ( $\mathrm{Li}$ and Qin, 2005; Martins et al., 2014). Besides invertebrates and microorganisms (including phytoplankton), macroalgae are important producer of bioactive compounds ( $\mathrm{Hu}$ et al., 2011, 2015).

Based on their chemical structures the identified marine natural products belong to several chemical groups: polyketides, terpenes, steroidal or triterpene saponins, carbohydrates, aliphatic compounds, amino acids, alkaloids, peptides, lipopeptides and proteins. The highest proportion of bioactive compounds belongs to peptides (Hu et al., 2015). Especially the number of new terpenoids from invertebrates is increasing, contrasting with the decreasing trend in the discovery of new alkaloids and aliphatic molecules (Leal et al., 2012).

From a pharmacological point of view, bioprospecting is directed mainly on compounds with cytostatic and cytotoxic activity. This can be explained by the ecological role of the compounds for defense, by the medicinal need for new antitumor drugs, by the availability of easily applicable in vitro test systems and by the support by funding agencies. A 2015 analysis found that anti-cancer compounds represented more than half of the new marine natural products discovered from 1985 to 2012 . This is followed by compounds with antibacterial activity (Hu et al., 2015). Compounds with anti-inflammatory (Cheung et al., 2016), antifungal, antiviral, analgetic and other activities get more and more importance (Mayer et al., 2010).

Marine bioprospecting started in geographic territories with long coast-line and warm temperatures. Regarding invertebrates (and probably also other groups of marine organisms) most were sampled in Asian marine areas, followed by Oceania, America, Africa and Europe (Leal et al., 2012).

Traditionally, the bioprospecting bases on biological activity or chemical guided search for new compounds. To be successful, rapid dereplication (identification of already known bioactive compounds) is necessary. Today, new analytical equipment, e.g. hyphenated techniques like LC-MS, LC/-MS/ MS or LC-NMR, and suitable databases are available to ensure that the attention can be directed to novel compounds (Gross, 2009; Martins et al., 2014; Pérez-Victoria et al., 2016). In future, genome mining will get more importance. In this concept, the exploitation of genetic information, also of nor- 
mally silent genes/gene clusters, is the key to the discovery of interesting compounds. The potential of genome mining can be expanded by the exploitation of metagenomics DNA from uncultivable microorganisms. However, it is applicable only for those types of secondary metabolites for which biosynthetic gene clusters can readily be identified by bioinformatics analysis. These classes are ribosomal and non-ribosomal peptides, polyketides and terpenes (Gross, 2009).

\section{MARINE DRUG DEVELOPMENT}

The process starts with collection and identification of the marine organisms. Collection of organisms at places easily to reach, at coasts or from the water surface, was preferred for a long time. Improvements in underwater life support systems have provided new possibilities for the collection from unexplored regions and depths. Identification requires in many cases genetic analyses. If possible, the collected and identified organisms should be taken into cultivation. If not, enough purified and dried material from the collection is necessary for further analysis (for expression in host cells see chapter Supply). In principle, the following steps are the same as for terrestrial organisms: extraction; biological and/or chemical and/ or genetic screening; identification and selection of interesting extracts; isolation and structure elucidation of compounds with promising biological activity and/or novel structures; broad pharmacological and toxicological investigations of drug candidates for pharmacodynamics, pharmacokinetic and safety parameter; target identification; ensure of supply; possibly derivatization and production of substance libraries and selection of best suitable candidate; clinical trials; registration according to the valid legislation (Kiuru et al., 2014; Martins et al., 2014). The website "The Global Marine Pharmaceuticals Pipeline", maintained by Alejandro M. S. Mayer of Midwestern University, IL, USA, tracks marine-derived drugs and gives summarizing information about licensed drugs and those in clinical trials. Presently about twenty marine-derived drugs are in clinical trials (Mayer, 2016).

\section{SUPPLY PROBLEM}

A critical point in the process of drug development from marine organisms and often a bottleneck is the permanent availability of sufficient amounts of organisms and compounds without harming the marine environment. Only if supply can be addressed in an economically and ecologically feasible fashion, marine drugs will get a chance on the market (Hart et al., 2000; Molinski et al., 2009; Martins et al., 2014). If collection from natural environment cannot be operated in a sustainable matter, the supply problem can be solved by processes of marine biotechnology (aquaculture/mariculture/fermenter cultivation; genetic engineering; enzymatic synthesis or modification) or by chemical synthesis/semi synthesis/modification (Lindequist and Schweder, 2001).

\section{Aquaculture/cultivation}

Aquaculture is well established for the production of marine animals like fishes or some mussels for food and for macroalgae. Cultivation in bioreactors is realized for macro- and microalgae, some types of invertebrate cells, marine fungi and several species of marine bacteria (Mendola, 2000; Lindequist and Schweder, 2001). However, the majority of pharmaceutically interesting marine organisms, especially microorganisms, cannot be cultured under artificial conditions. Better understanding of living conditions in natural environment is necessary to develop alternative cultivation methods and to maintain the metabolite production over a long time. One promising way could be the co-cultivation, also called mixed fermentation, of two or more different organisms, mainly microorganisms, which tries to mimic the complex communities in nature. It could be shown that co-cultivation extends the chemical diversity of metabolites produced by the cultivated organisms. It leads to a significantly enhanced production of constitutively present compounds and/or to an accumulation of cryptic compounds that are not detected in axenic cultures of the producing strain (Marmann et al., 2014).

\section{Genetic engineering}

Principle of this method is the transfer of the genetic information for the desired compound into host cells, which can be easier cultivated, and the sustainable production of the compound in the host cells. Prerequisite is the exact knowledge of the genetic information. Such techniques would permit the isolation and expression of genes of organisms, which cannot be cultivated. Up till now, this approach is realized on research level but not in industrial scale for marketable marine drugs.

\section{Synthesis/semi synthesis/modification}

Although total synthesis is principally possible for many of the known marine compounds, it can be economically realized only for relatively simple products. One example is the analgetic peptide ziconotide. Another way can be the semisynthetic production where easily available compounds are transferred by chemical or biochemical processes into the desired product. An example for this concept is the production of trabectedin by transformation of cyanosafracin $B$, a bacterial product. In most cases, the original natural compound is a "lead structure" and it is not necessary to produce the whole structure. The more we know about the structural elements that are necessary for pharmacological effect, the more we can focus on the essential structural components. The halichondrine derivate eribulin is a synthetic molecule which is much smaller than the natural original compound (Newman and Cragg, 2016). Chemical and/or enzymatic modifications of the natural compound as lead structure can increase the structural variability and improve the properties of the product (Lindequist and Schweder, 2001; Radjasa et al., 2011).

\section{MARINE COMPOUNDS AS CYTOSTATIC DRUGS}

Worldwide tumor diseases range at position three in mortality statistics. New antitumor drugs with high activity and minimized side effects are urgently needed. Marine natural compounds can contribute to meet this demand. The development of marine cytostatics started with the already mentioned discovery of the nucleosides sphongothymidine (Fig. 1A) and spongouridine (Fig. 1B) from the Caribbean sponge Tethya crypta (Bergmann and Feeney 1951; Bergmann and Burke, 1955; Newman and Cragg, 2016). The sponge is presently named Tectytethya crypta and was formerly also known as Cryptotethya crypta. Based on this discovery the synthetic an- 
A<smiles>Cc1cn(C2OC(CO)[C@@H](O)[C@H]2O)c(=O)[nH]c1=O</smiles>

B<smiles>O=c1ccn(C2OC3OC2C(CO)C3O)c(=O)[nH]1</smiles>

C<smiles>Nc1ccn(C2OC3OC2C(CO)C3O)c(=O)n1</smiles>

D<smiles>Nc1ncnc2c1ncn2[C@@H]1O[C@H](CO)[C@@H](O)[C@H]1O</smiles>

Fig. 1. Structures of sponge nucleosides spongothymidine (A), spongouridine (B) and derivatives of sponge nucleosides cytarabine (C) and vidarabine (D).

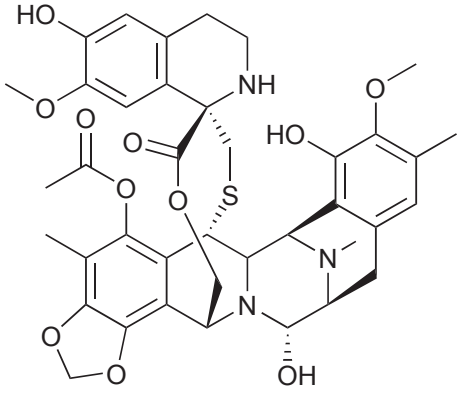

Fig. 2. Structure of trabectedin.

alogue cytosine arabinoside cytarabine (e.g. Cytosar-U, Pfizer, Kirkland, Quebec, Canada, Fig. 1C) has been developed as a potent antileukemic agent and approved by Food and Drug Administration (FDA, MD, USA) in 1969. This pyrimidine nucleoside is a prodrug. It is intracellularly converted to cytosine arabinoside triphosphate, which competes with the physiological substrate deoxycytidine. By this way DNA polymerase and therefore DNA synthesis are inhibited. It is used in the treatment of acute myeloid leukemia, as well as other forms of leukemia and non-Hodgkin's lymphoma (Löwenberg, 2013). Dosage depends on type of cancer and stadium of therapy. Side effects are mainly gastrointestinal disorders. Furthermore pneumonia, anorexia and confusion can occur. Liposomal cytarabine (Depocyt, Mundipharma, Limburg, Germany) is indicated for intrathecal treatment of lymphomatous meningitis. Gemcitabin (e.g. Gemzar, Lilly Deutschland GmbH, Giessen, Germany) is difluor-cytarabine and indicated for the treatment of bladder, pancreas, mamma, ovarian and bronchial cancer (Mayer et al., 2010; Anjum et al., 2016; Mutschler et al., 2016).

Trabectedin (Ecteinascidin, ET-743, Yondelis, PharmaMar, Colmenar Viejo, Spain, Fig. 2) has been first isolated from the ascidian Ecteinascidia turbinata. The animals live on corals in the Mediterranean and produce the compound to protect themselves against microorganisms. New observations and genetic analysis let assume that trabectedin is produced by as yet uncultivated microorganisms associated with the tunicates (Giddings and Newman, 2013; Schofield et al., 2015). Trabectedin belongs chemically to the group of tetrahydroisoquinoline alkaloids. It is composed of 3 tetrahydroquinoline moieties, 8 rings including one 10-membered heterocyclic ring containing a cysteine residue and 7 chiral centers. It can be produced in sustainable amount by semi synthetic transformation of cya-

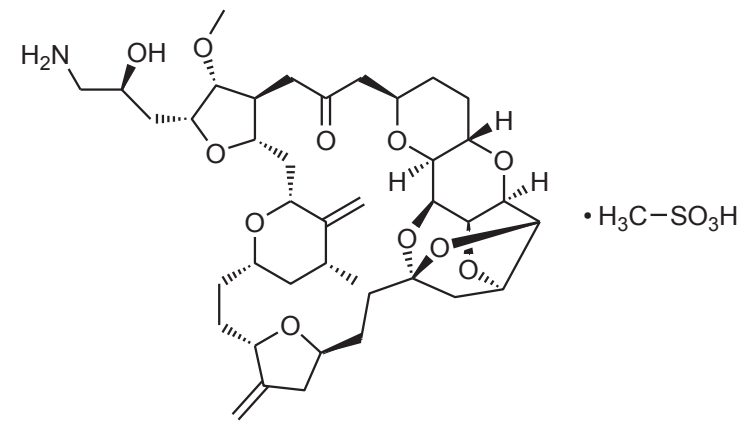

Fig. 3. Structure of eribulin mesylate.

nosafracin B, a product of the bacterium Pseudomonas fluorescens (Cuevas and Francesch, 2009). Trabectedin appears to represent a new class of anti-neoplastic compounds acting both on cancer cells and on the tumor microenvironment. Its cytostatic activity is related to binding to specific triplets of the DNA minor groove and to direct effects on transcription regulation. It prevents transcription by preventing the binding of transcription factors to DNA. The formed adducts functionally mimic an inter-strand cross-linking lesion which blocks transcription by stabilizing double-strand DNA. Besides, it interacts directly with the elongating RNA polymerase II (Pol II). The tumor microenvironment is affected by limiting the number of tumor-associated macrophages and modulating the production of cytokines and angiogenic factors. A therapeutic synergism of the effects of trabectedin on tumor cells and on the microenvironment can be expected. In opposite to other DNAinteracting anticancer drugs like platinum-based compounds NER (nucleotide excision repair)-deficient cells are less sensitive to trabectedin than NER-proficient cells (D'Incalci et al., 2014; Löpez-Guerrero et al., 2015). The European Union (EU) approved trabectedin in 2007, the FDA in 2015. It is registered for the treatment of adult patients with advanced soft tissue sarcoma, after failure of anthracyclines and iosfamide, or patients, which are unsuited to receive these agents. In combination with pegylated liposomal doxorubicin it is approved for patients with relapsed platin-sensitive ovarian cancer. An open phase III multi-center study with 672 patients with recurrent ovarian carcinoma which were treated with a combination of trabectedin with pegylated liposomal doxorubicin showed a significantly longer progression-free survival (6 weeks) than doxorubicin monotherapy alone. The tolerability profile was the same as under the doxorubicin therapy alone (Carter and 
Keam, 2010; D'Incalci et al., 2014). Recently, long-term response to first-line trabectedin in an elderly female patient with a metastatic leiomyosarcoma has been shown (Maruzzo et al., 2016). Trabectedin can be evaluated as a valuable addition to second-line therapy after failure of first-line chemotherapy. Typical dose for treatment of soft tissue is $1.5 \mathrm{mg} / \mathrm{m}^{2}$, i.v. during $24 \mathrm{~h}$ every three weeks (Mutschler et al., 2016). The drug is eliminated through hepatic metabolism and CYP3A4 is the principal responsible enzyme. Interactions with drugs which are also metabolized by this enzyme are possible (Brandon et al., 2006). Rhabdomyolysis is an uncommon adverse reaction associated with trabectedin treatment with an incidence of $0.7 \%$. Close patient monitoring, especially during the first 3 cycles, and adequate treatment adjustments in cases of severe myelosuppression and liver dysfunction are mandatory (Grosso et al., 2012).

Eribulin mesylate (Halaven, Eisai Europe Ltd., Hatfield, Hertfordshire, UK, Fig. 3) is a synthetic analogon of halichondrin $B$ which has been isolated from marine sponges, e.g. Halichondria okadai and Lyssodendoryx sp. Biochemically it belongs to polyketides nontaxane derivatives. Halichondrin B is a prominent example for the supply problem. Just $300 \mathrm{mg}$ of halichondrin B originated from a $1 \mathrm{t}$ collection of Lissodendoryx $\mathrm{n} . \mathrm{sp} .1$, a rare deep water sponge species. This very low yield did not allow the sustainable isolation of halichondrin $B$ (Hart et al., 2000; Radjasa et al., 2011). Today we know that halichondrin $B$ is probably not produced by the sponges but by dinoflagellates that live symbiontic in the sponges. In the case of halichondrin the supply problem was solved by chemical synthesis (Aicher et al., 1992)

The drug was approved by the FDA in 2010 and by the EU in 2011 for patients with locally advanced or metastatic breast cancer who have progressed after at least 2 (since 2014 after 1) chemotherapeutic regimens for advanced disease. By influencing the dynamics of microtubule in a complex matter, the compound inhibits the growth phase of microtubules and sequesters tubulin into nonproductive aggregates. This leads to G2/M arrest of cell cycle, disruption of mitotic spindles and apoptotic cell death (Smith et al., 2010). Eribulin mesylate is administered intravenously over 2 to $5 \mathrm{~min}$ on days 1 and 8 of a 3-week cycle. The recommended dose of eribulin is 1.23 $\mathrm{mg} / \mathrm{m}^{2}$, those of eribulin mesylate $1.4 \mathrm{mg} / \mathrm{m}^{2}$. In the pivotal trial with patients with locally advanced or metastatic breast cancer after 2 prior chemotherapy lines the median survival in the eribulin group was 13.2 months, in the control group 10.6 months (HR=0.805; 95\% confidence interval, 0.677-0.958; $p=0.014)$. The most common side effects are asthenia or fatigue and neutropenia (Morris, 2010; Pean et al., 2012).

In Brentuximab vedotin (Adcetris, Takeda Pharma A/S, Taastrup, Denmark) the interesting principle of combining a highly cytotoxic compound with a tumor specific antibody is realized. It consists of the cytotoxic compound monomethyl auristatin (MMAE, Fig. 4) and an antibody directed against CD30 on the surface of tumor cells such as those in Hodgkin lymphoma or systemic anaplastic large cell lymphoma (ALCL). Both components are linked through an enzyme-cleavable valine-citrulline dipeptide (Doronina et al., 2006; Ansell, 2011). Auristatin is a synthetic analogue of the marine natural product dolastatin 10. The dolastatins are a series of cytotoxic peptides that were originally isolated in very low amounts from the Indian Ocean mollusk Dolabella auricularia. Today we know that the true producer of dolastatins are cyanobacteria of the

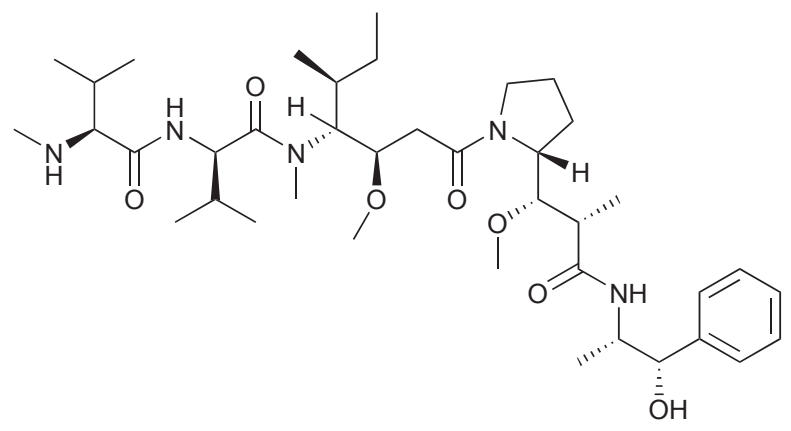

Fig. 4. Structure of monomethyl auristatin.

genus Symploca (Luesch et al., 2001), recently renamed into the new genus Caldora and species penicillata (Engene et al., 2015). Dolastatin 10 is a linear depsipeptide. Because of its high toxicity it cannot be administered alone but by the help of the conjugated antibody it can be addressed directly to the tumor cells carrying the specific antigen.

After intravenous application brentuximab vedotin binds to the extracellular domain of CD30, becomes internalized by clathrin-mediated endocytosis, and subsequently travels to the lysosome where proteases cleave the linker peptide and release MMAE into the cytosol (Sutherland et al., 2006). It binds to tubulin and potently inhibits microtubule polymerisation, inducing G2/M phase arrest in cell cycle and apoptosis. By diffusion into the microenvironment of the CD30 carrying cells MMAE can influence also CD30 negative lymphoma cells (Fromm et al., 2012).

The FDA approved it in 2011 for the treatment of patients with Hodgkin lymphoma relapsed after autologous stem-cell transplantation (ASCT), or after two multidrug regimes in patients with Hodgkin lymphoma who are not candidates for ASCT, and for patients with systemic anaplastic large cell lymphoma (ALCL) who failed at least one prior multidrug chemotherapy regime. The recommended dosage is $1.8 \mathrm{mg} / \mathrm{kg}$ body weight, i.v., three weekly (Mutschler et al., 2016). The overall objective response rate in a noncomparative multicenter phase II trial was $75 \%$ in 102 patients with Hodgkin lymphoma who had relapsed after high-dose chemotherapy and autologous haematopoetic stem cell transplantation (Younes et al., 2012). The overall objective response rate in 58 patients with relapsed $A L C L$ after at least one prior treatment was $86 \%$ in the same trial type (Pro et al., 2012). Tumor reductions were observed in $94 \%$ of patients with Hodgkin lymphoma and $97 \%$ of patients with systemic ALCL. The estimated 12-month survival rates were $89 \%$ and $52 \%$, respectively. The dose-limiting non haematological toxicity is peripheral neuropathy, which is potentially reversible. Currently there are several clinical studies, which prove the effectiveness of combination of brentuximab vedotin with other antitumor drugs (Deng et al., 2013; Garnock-Jones, 2013). Further antibody-drug conjugates, e.g. glembatumumab vedotin against breast cancer in phase II, are presently in clinical trials (Newman and Cragg, 2016).

\section{MARINE COMPOUNDS AS ANTIVRAL DRUGS}

The development of vidarabine (arabinofuranosyladenine, adenin arabinoside, Ara-A, Fig. 1D) results from the first inves- 


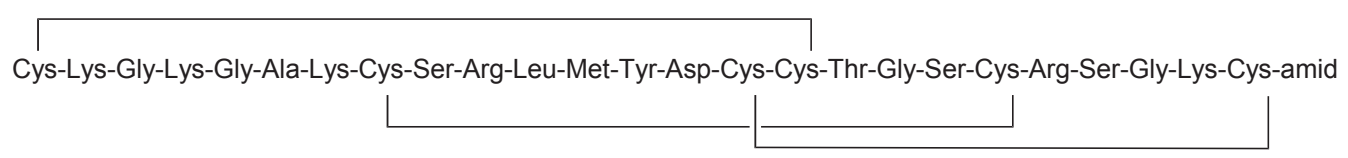

Fig. 5. Structure of ziconotide.

tigations of sponge nucleosides as possible drugs in the 1950s (see above). Intracellularly vidarabine is rapidly converted into adenine arabinoside triphosphate. This activated form inhibits DNA polymerase and DNA synthesis of herpes, vaccinia and varicella zoster viruses. In the EU, it is used in the form of eye drops for the treatment of acute keratoconjunctivitis, recurrent epithelial keratitis caused by herpes simplex type 1 and 2 . In the USA, its approval was discontinued by June 2001 possibly due to its restricted therapeutic window (Mayer et al., 2010; Sagar et al., 2010; Martins et al., 2014; Anjum et al., 2016).

\section{MARINE COMPOUNDS AS ANALGETIC DRUGS}

Severe chronic pain affects millions of people worldwide. Standard medication includes opioids like morphine. However, opiod analgetics have several disadvantages like development of dependency and tolerance, possibility of abuse and severe side effects like respiratory suppression and obstipation. Therefore, alternative or additional strong analgetics are needed. Ziconotide (Prialt, Jazz Pharmaceuticals plc, Dublin, Ireland, Fig. 5), a synthetic peptide based on a toxin of the poisonous marine cone snail Conus magus, can be such an alternative. The snails produce in their envenomation apparatus a venom consisting of different peptide toxins, named conotoxins (or conopeptides), for defense and prey capture. In nature, the venom is injected into fish and leads within few seconds to paralysis. It is highly poisonous also for human. One of the conotoxins, $\omega$-conotoxin (SNX-111, MVIIA), is the natural model for the synthetic peptide ziconotide. It consists of $25 \mathrm{~L}$-amino acids, has a molecular weight of 2,639 Da and is a highly polar and water-soluble molecule. The three disulfide bonds determine the 3-dimensional structure and are necessary for biological effect. It selectively targets neuronspecific ( $\mathrm{N}$-type), voltage-gated calcium channels and produces potent analgesia by interruption of $\mathrm{Ca}$-dependent primary afferent transmission of pain signals in the spinal cord (Olivera et al., 1985; Miljanich, 2004; Terlau and Olivera, 2004). Since 2004 it is approved for patients with severe chronic pain, including neuropathic pain and especially for those refractory to opioids. The efficacy of ziconotide against malignant and non-malignant pain has been demonstrated in several clinical studies. Adverse events affect primarily the central nervous system, e.g. dizziness, nausea and confusion. It is not recommended for patients with neurological and psychiatric symptoms. Ziconotide has to be administered by direct injection into spinal fluid. It is mainly distributed within the cerebral spinal fluid. In the systemic circulation it is rapidly metabolized by proteolysis so that there are only negligible amounts. The halflife in blood is approximately 1 hour, in the cerebral spinal fluid about 5 hours. Because of lag-time for the onset and offset of analgetic and adverse effects, the initial doses should be low (about $2.4 \mu \mathrm{g} /$ day). It should be gradually increased up to a
A

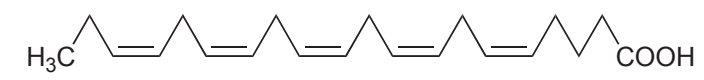

B

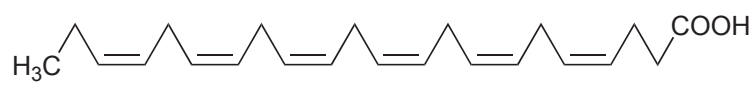

Fig. 6. Structures of eicosapentaenoic acid (A) and docosahexaenoic acid (B).

maximum of $21.6 \mu \mathrm{g} /$ day in steps of $2.4 \mu \mathrm{g} /$ day no more than twice weekly. The analgetic effect maintains over months and does not cause tolerance. In opposite to morphine, ziconotide does not lead to dependency or respiratory depression (Klotz, 2006). Besides $\omega$-conotoxin, several other conotoxines and their derivatives possess interesting pharmacological activities and are promising tools for drug development (Ramasamy et al., 2011; Newman and Cragg, 2016).

\section{MARINE COMPOUNDS AS ANTIHYPERLIPIDEMIC DRUGS}

Eicosapentaenoic acid (EPA) and docosahexaenoic acid (DHA) are important polyunsaturated fatty acids (PUFAs, Fig. 6). They have numerous beneficial properties for human health, e.g. prevention of blood-circulatory diseases like thrombosis and arteriosclerosis, protection of cognitive functions in aging (Witte et al., 2014) and for infant development. The overall capacity of human organism to synthesize these fatty acids is relatively low so that they have to be consumed from dietary sources or, for a fetus or a breast fed baby, from the mother. The most important source is fish oil. Because of disturbing taste and smell of fish-derived PUFA products and the problem that fish stocks continue to dwindle worldwide lower marine organisms such as microalgae play an increasing role as producer of PUFAs.

Photoautotrophic microalgae like Nannochloropsis can be cultivated in an industrial scale and accumulate considerable amounts of their cell mass as lipids (Chini Zitelli et al., 1999; Lindequist and Schweder, 2001). The screening of microbial PUFA synthesis genes from metagenome libraries allowed the cloning of the responsible genes and the expression in suitable hosts like Escherichia coli and Synechococcus spp. (Takeyama et al., 1997; Schweder et al., 2005).

Ethyl esters of eicosapentaenoic acid and docosahexaenoic acid are approved drugs (e.g. Lovaza, Glaxo Smith Kline, Brentford, Middlesex, UK), which are produced through esterification of the natural fatty acids. They are used in combination with diet and/or statins, inhibitors of thrombocyte aggregation and antihypertensive drugs to normalize and control 
the triglyceride level in human blood in the frame of secondary prophylaxis after heart infarct (1 g per day, p.o.) and in patients with endogenous hypertriglyceridemia (1-2 g, 2 times per day, p.o.). Possible side effects are gastrointestinal disorders and increase of transaminases (Koski, 2008; Martins et al., 2014; Mutschler et al., 2016).

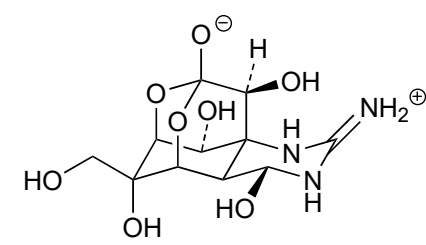

Fig. 7. Structure of tetrodotoxin.

\section{MARINE COMPOUNDS AS DIAGNOSTICS AND EXPERIMENTAL TOOLS}

The enzyme Taq polymerase, irreplaceable for polymerase chain reaction (PCR), was first isolated from the bacterium Thermus aquaticus, living in hot springs (Mullis and Falcona, 1987). Meanwhile other enzymes from hot springs and marine environment have been reported. Pfu, an enzyme from the marine thermophile Pyrococcus furiosus, is now also used in PCR (Cline et al., 1996; Burgess, 2012).

GFP, green fluorescent protein, was first isolated from the jellyfish Aequorea victoria. It is used as biological marker for labelling of cellular structures in vitro and in vivo (Mocz, 2007; Shimomura, 2009; Burgess, 2012). Shimomura (Japan), Chalfie and Tsien (USA) got the Nobel Price for its detection and establishment of its applications in 2008. For similar purposes, phycoerythrin and other pigments from photoautotrophic cyanobacteria are used. In producing organisms GFP and simi-

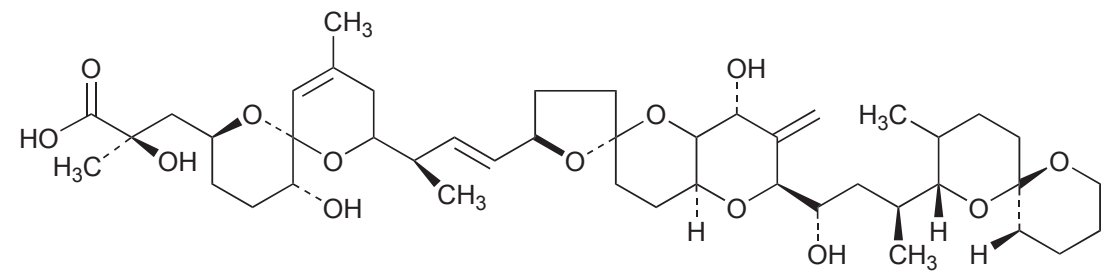

Fig. 8. Structure of okadaic acid.

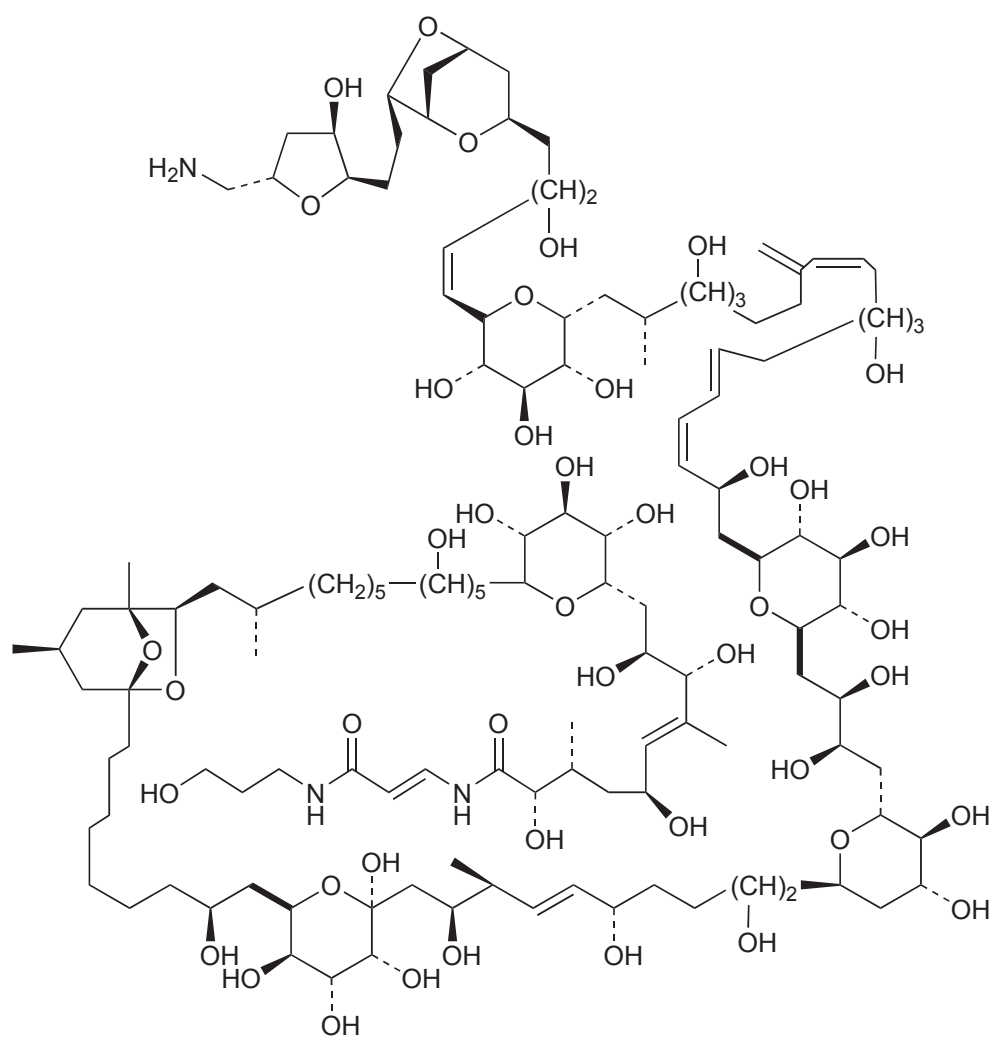

Fig. 9. Structure of palytoxin. 
lar proteins have possibly the function to act as light driven electron transfer (Bogdanov et al., 2009).

LAL, Limulus-Amoebocyte-Lysate from the crab Limulus polyphemus, is utilized in the form of the LAL test for the sensitive detection of pyrogenic lipopolysaccharides (LPS) from gram-negative bacteria. Actual pharmacopoeia, e.g. European Pharmacopoeia, prescribe the LAL test to check the absence of LPS in parenteralia (Council of Europe, 2014).

Keyhole limpet hemocyanin (KLH) is a large, multisubunit, oxygen-carrying metalloprotein which is found in the hemolymph of the giant keyhole limpet Megathura crenulata, a marine mollusk, living off the coasts of California, USA. The protein complex can be harvested from cultures of the limpet. It is used as hapten carrier, as vaccine component und clinically for the treatment of bladder carcinoma (Harris and Markl, 1999).

Some strong marine toxins have got importance as experimental tools because of their specific targets and mode of activity. As examples tetrodotoxin, okadaic acid and palytoxin should be named. The chinazoline alkaloid tetrodotoxin (Fig. 7 ) is well known as secondary toxin in puffer fishes ("Fugu"). It is produced by marine bacteria and comes into fishes over the food chain. It targets very specific $\mathrm{Na}^{+}$ion channels and can be used for investigation of physiological processes mediated by those ion channels (Teuscher and Lindequist, 2010; Bane et al., 2014). Besides, it is presently in clinical trial (Tectin, WEX Pharmaceuticals Inc., Vancouver, Canada, Phase III) against inadequately controlled pain related to cancer (Mayer, 2016; Newman and Cragg, 2016).

Okadaic acid (Fig. 8) is a specific inhibitor of serine/threonine phosphatases. This polyketide is produced by dinoflagellatae (Dinophysis sp., Prorocentrum sp.) and one cause of diarrhetic shellfish poisoning (DSP) in human. The compound is a useful tool to study mechanisms of diseases which are associated with protein phosphorylation, e.g. Alzheimer's disease (Teuscher and Lindequist, 2010; Kamat et al., 2014). Palytoxin (Fig. 9) is a very large polyketide, produced by marine microbes and first isolated from sponges (Palythoa sp., Zoanthidae). It has a very specific mode of action at $\mathrm{Na}^{+} / \mathrm{K}^{+}$pumps in membranes leading to different secondary effects. It can be used for analysis of structure and mechanisms of such ion pumps (Wu, 2009; Teuscher and Lindequist, 2010).

\section{CONCLUSION AND OUTLOOK}

The recent advances in development, approval and therapeutic use of marine drugs demonstrate the enormous potential of marine natural products. Presently, seven FDA or EMA approved drugs from marine organisms, mostly antitumor drugs, are on the market. Approximately 20 candidates are presently in clinical trials Phase I, I/II, II or III (Mayer, 2016; Newman and Cragg, 2016). A very promising candidate is salinosporamide $A$ (marizomib). This orally active $\beta$-lactone is produced by the actinomycete Salinispora tropica. It inhibits the 20S proteasome and is in clinical development for the treatment of various hematological malignancies and solid tumors, especially of multiple myeloma (Fenical et al., 2009). Although cancer will stay the main indication, an extension of the spectrum of indications can be expected, e.g. a candidate against Alzheimer disease that targets nicotinergic acetylcholine receptors is in Phase II (DMXBA, Mayer, 2016). Already now, the market for marine nutraceuticals and cosmetics is continuously increasing.

Nevertheless, there are many challenges to further exploit the potential of marine organisms for medicinal purposes. It seems necessary to give more emphasis to the following fields:

\section{Taxonomy/genetics}

Correct taxonomic determination of the producing organism is essential for further processes. Genetic barcoding in combination with morphological taxonomy and chemotaxonomy will allow exact taxonomic determination. Because many marine organisms cannot be cultured under artificial conditions they are not accessible for detailed taxonomical and physiological characterizations. Nevertheless, with the today available advanced molecular techniques we are able to identify and characterize organisms and populations without cultivation.

The concept of genome mining will strongly increase the probability of finding new bioactive structures. In metagenomic approaches functional gene clusters from uncultured organisms and communities of different organisms can be screened by isolating genetic material directly from original environmental samples, cloning and transformation of these sequences into a suitable host vector system and its expression in the host cells. Further omics technologies like proteome, transcriptome and metabolome analysis will help to understand biosynthesis and physiological importance of the interesting metabolites (Schweder et al., 2005; Gross, 2009; Martins et al., 2014).

\section{Supply/cultivation}

Advancement in sampling techniques will allow access to marine samples, which are not only near-shore but e.g. also in the deep sea (Skropeta, 2008; Martins et al., 2014). Special fermentation technologies are necessary to cultivate organisms living in nature under extreme conditions like high pressure. Many biosynthetic genes, especially those of axenic cultivated microorganisms, remain silent under artificial conditions. Strategies that could overcome these limitations and increase the chemical diversity are variation of culture conditions (OSMAC approach), epigenetic modifications or co-cultivation (Marmann et al., 2014). By the help of genome mining techniques it will be possible to waive cultivation of the original producing organisms and to express the genetic information in suitable expression systems (Gross, 2009). Better understanding of essential structure elements (pharmacophore) and advances in chemical synthesis will help to design structures of reduced complexity and to develop economically feasible synthesis procedures (Martins et al., 2014). Substance libraries basing on one scaffold increase the chance to find suitable candidates.

\section{Pharmacology/drug development}

Empirical cell-based screening for cytotoxicity will be completed by screening for other pharmacological activities, by using specific targets and by application of high content methods (HCT). Intelligent coupling of cellular tests with omics technologies will help to identify interesting drug candidates, to clarify mode of action and to avoid late stage failure of compounds in the pipeline. More attention should be given to early investigation of toxicological risks and to pharmacokinetic behavior of the drug candidates. 


\section{Market access}

The requirements to get access to the market are of course the same for marine-derived drugs as for terrestrial drugs. This means that the approval requires long time (typically an 8- to 15-year period) and a lot of money (in average US $\$ 900$ million) from discovery to market (Snelgrove, 2016). There is a very high risk of failures and many promising marine compounds have failed during the development processes because of toxicity, not sustainable availability and other facts.

The success of marine pharmaceuticals development will highly depend upon the intensive interdisciplinary collaboration between biologists, chemists, biotechnologists, pharmacists, medical doctors etc. and between universities, hospitals and companies.

\section{REFERENCES}

Aicher, T. D., Buszek, K. R., Fang, F. G., Forsyth, C. J., Jung, S. H., Kishi, Y., Matelich, M. C., Scola, P. M., Spero, D. M. and Yoon, S. K. (1992) Total synthesis of halichondrin B and norhalichondrin B. J. Am. Chem. Soc. 114, 3162-3164.

Anjum, K., Abbas, S. Q., Shah, S. A., Akhter, N., Batool, S. and Hassan, S. S. (2016) Marine sponges as drug treasure. Biomol.Ther. (Seoul) 24, 347-362.

Ansell, S. M. (2011) Brentuximabvedotin: delivering an antimitotic drug to activated lymphoma cells. Expert Opin. Investig. Drugs 20, 99105.

Bane, V., Lehane, M., Dikshit, M., O’Riordan, A. and Furey, A. (2014) Tetrodotoxin: chemistry, toxicity, source, distribution and detection. Toxins 6, 693-755.

Bergmann, W. and Burke, D. C. (1955) Marine products. XXXIX. The nucleosides of sponges. III. Spongothymidine and spongouridine. J. Org. Chem. 20, 1501-1507.

Bergmann, W. and Feeney, R. J. (1951) Contributions to the study of marine products. XXXII. The nucleosides of sponges. J. Org. Chem. 16, 981-987.

Blunt, J. W., Copp, B. R., Keyzers, R. A., Munro, M. H. and Prinsep, M. R. (2016) Marine natural products. Nat. Prod. Rep. 33, 382-431.

Bogdanov, A. M., Mishin, A. S., Yampolsky, I. V., Belousov, V. V., Chudakov, D. M., Subach, F. V., Verkhusha, W., Lukyanov, S. and Lukyanov, K. A. (2009) Green fluorescent proteins are light-induced electron donors. Nat. Chem. Biol. 5, 459-461.

Bongiorni, L. and Pietra, F. (1996) Marine natural products for industrial applications. Chem. Ind. 2, 54-58.

Brandon, E. F., Sparidans, R. W., Guijt, K. J., Lowenthal, S., Meijerman, I., Beijnen, J. H. and Schellens, J. H. (2006) In vitro characterization of the human biotransformation and CYP reaction phenotype of ET-743 (Yondelis, Trabectedin), a novel marine anti-cancer drug. Invest. New Drugs 24, 3-14.

Burgess, J. G. (2012) New and emerging analytical techniques for marine biotechnology. Curr. Opin. Biotechnol. 23, 29-33.

Caron, D. A., Countway, P. D., Jones, A. C., Kim, D. Y. and Schnetzer, A. (2012) Marine protistan diversity. Ann. Rev. Mar. Sci. 4, 467-493.

Carter, N. J. and Keam, S. J. (2010) Trabectedin: a review of its use in soft tissue sarcoma and ovarian cancer. Drugs 70, 355-376.

Census of marine life [Internet] Office of Marine Programs, University of Rhode Island, Graduate School of Oceanography; c2010 [cited 2016 Aug 03]. Available from: http://www.coml.org/.

Cheung, R. C., Ng, T. B., Wong, J. H., Chen, Y. C. and Chan, W. Y. (2016) Marine natural products with anti-inflammatory activity. Appl. Microbiol. Biotechnol. 100, 1645-1666.

Chini Zitelli, G., Lavista, F., Bastianini, A., Rodolfi, L., Vincenzini, M. and Tredici, M. R. (1999) Production of eicosapentaenoic acid by Nannochloropsis sp. cultures in outdoor tubular photobioreactors. J. Biotechnol. 70, 299-312.

Cline, J., Braman, J. C. and Hogrefe, H. H. (1996) PCR fidelity of Pfu DNA polymerase and other thermostable DNA polymerases. Nucleic Acids Res. 24, 3546-3551.
Council of Europe (2014) European Pharmacopoeia (Ph. Eur.) (8th edition). Council of Europe.

Cuevas, C. and Francesch, A. (2009) Development of Yondelis (trabectedin, ET-743). A semisynthetic process solves the supply problem. Nat. Prod. Rep. 26, 322-337.

Debbab, A., Aly, A. H., Lin, W. H. and Proksch, P. (2010) Bioactive compounds from marine bacteria and fungi. Microb. Biotechnol. 3, 544-563.

Deng, C., Pan, B. and O'Connor, O. A. (2013) Brentuximab Vedotin. Clin. Cancer Res. 19, 22-27.

Doronina, S. O., Mendelsohn, B. A., Bovee, T. D., Cerveny, C. G., Alley, S. C., Meyer, D. L., Oflazoglu, E., Toki, B. E., Sanderson, R. J., Zabinski, R. F., Wahl, A. F. and Senter, P. D. (2006) Enhanced activity of monomethylauristatin $F$ through monoclonal antibody delivery: effects of linker technology on efficacy and toxicity. Bioconjug. Chem. 17, 114-124.

D'Incalci, M., Badri, N., Galmarini, C.M. and Allavena, P. (2014) Trabectedin, a drug acting on both cancer cells and the tumour microenvironment. Br. J. Cancer 111, 646-650.

Engene, N., Tronholm, A., Salvador-Reyes, L. A., Luesch, H. and Paul, V. J. (2015) Caldora penicillata gen. nov., comb. nov. (Cyanobacteria), a pantropical marine species with biomedical relevance. J. Phycol. 51, 670-681.

Faulkner, D. J., Harper, M. K., Haygood, M. G., Salomon, C. E. and Schmidt, E. W. (2000) Symbiotic bacteria in sponges: sources of bioactive substances. In Drugs from the Sea (N. Fusetani, Ed.), pp. 107-119. Karger, Basel.

Fenical, W., Jensen, P. R., Palladino, M. A., Lam, K. S., Lloyd, G. K. and Potts, B. C. (2009) Discovery and development of the anticancer agent salinosporamide A (NPI-0052). Bioorg. Med. Chem. 17 2175-2180.

Fromm, J. R., McEarchem, J. A., Kennedy, D., Thomas, A., Shustov, A. R. and Gopal, A. K. (2012) Clinical binding properties, internalization kinetics, and clinic-pathological activity of brentuximab vedotin: an antibody-drug conjugate for CD30-positive lymphoid neoplasms. Clin. Lymphoma Myeloma Leuk. 12, 280-283.

Garnock-Jones, K. P. (2013) Brentuximab vedotin: a review of its use in patients with Hodgkin lymphoma and systemic anaplastic large cell lymphoma following previous treatment failure. Drugs 73, 371381.

Giddings, L. A. and Newman, D. J. (2013) Microbial natural products: molecular blue-prints for antitumor drugs. J. Ind. Microbiol. Biotechnol. 40, 1181-1210.

Gross, H. (2009) Genomic mining - a concept for the discovery of new bioactive natural products. Curr. Opin. Drug Discov. Devel. 12, $207-$ 219.

Grosso, F., D’Incalci, M., Cartáoafa, M., Nieto, A., Fernández-Teruel, C., Alfaro, V., Lardelli, P., Roy, E., Gómez, J., Kahatt, C., SotoMatos, A. and Judson, I. (2012) A comprehensive safety analysis confirms rhabdomyolysis as an uncommon adverse reaction in patients treated with trabectedin. Cancer Chemother. Pharmacol. 69, 1557-1565.

Harris, J. R. and Markl, J. (1999) Keyhole limpet hemocyanin (KLH): a biomedical review. Micron 30, 597-623.

Hart, J. B., Lill, R. E., Hickford, S. J. H., Blunt, J. W. and Munro, M. H. G. (2000) The halichondrins: chemistry, biology, supply and delivery. In Drugs from the Sea (N. Fusetani, Ed.), pp. 134-153. Karger, Basel.

Hill, R. T. and Fenical, W. (2010) Pharmaceuticals from marine natura products: surge or ebb? Curr. Opin. Biotechnol. 21, 777-779.

Hu, G. P., Yuan, J., Sun, L., She, Z. G., Wu, J. H., Lan, X. J., Zhu, X., Lin, Y. C. and Chen, S. P. (2011) Statistical research on marine natural products based on data obtained between 1985 and 2008 . Mar. Drugs 9, 514-525.

Hu, Y., Chen, J., Hu, G., Yu, J., Zhu, X., Lin, Y., Chen, S. and Yuan, J. (2015) Statistical research on the bioactivity of new marine natural products discovered during the 28 years from 1985 to 2012. Mar. Drugs 13, 202-221.

Jensen, P. R. and Fenical, W. (2000) Marine microorganisms and drug discovery: current status and future potential. In Drugs from the Sea (N. Fusetani, Ed.), pp. 6-29. Karger, Basel.

Kamat, P. K., Rai, S., Swarnkar, S., Shukla, R. and Nath, C. (2014) 
Molecular and cellular mechanisms of okadaic acid (OKA)-induced neurotoxicity: a novel tool of Alzheimer's disease therapeutic application. Mol. Neurobiol. 50, 852-865.

Kiuru, P., D'Auria, M. V., Muller, C. D., Tammela, P., Vuorela, H. and Yli-Kauhaluoma, J. (2014) Exploring marine resources for bioactive compounds. Planta Med. 80, 1234-1246.

Klotz, U. (2006) Ziconotide - a novel neuron-specific calcium channel blocker for the intrathecal treatment of severe chronic pain - a short review. Int. J. Clin. Pharmacol. Ther. 44, 478-483.

Koski, R. R. (2008) Omega-3-acid ethyl esters (lovaza) for severe hypertriglyceridemia. $P$ T 33, 271-303.

König, G. M. (1992) Meeresorganismen als Quelle pharmazeutisch bedeutsamer Naturstoffe. Dtsch. Apoth. Ztg. 132, 673-683.

Leal, M. C., Madeira, C., Brandão, C. A., Puga, J. and Calado, R. (2012) Bioprospecting of marine invertebrates for new natural products - a chemical and zoogeographical perspective. Molecules 17, 9842-9854.

Li, X. and Qin, L. (2005) Metagenomics-based drug discovery and marine microbial diversity. Trends Biotechnol. 23, 539-543.

Lindequist, U. and Schweder, T. (2001) Marine Biotechnology. In Biotechnology, Vol. 10: Special processes (H. J. Rehm, Ed.), pp. 441484. Wiley-VCH, Weinheim.

Luesch, H., Moore, R. E., Paul, V. J., Mooberry, S. L. and Corbett, T. H. (2001) Isolation of dolastatin 10 from the marine cyanobacterium Symploca species VP642 and total stereochemistry and biological evaluation of its analogue symplostatin 1. J. Nat. Prod. 64, 907910.

Löpez-Guerrero, J. A., Romero, I. and Poveda, A. (2015) Trabectedin therapy as an emerging treatment strategy for recurrent platinumsensitive ovarian cancer. Chin. J. Cancer 34, 41-49.

Löwenberg, B. (2013) Sense and nonsense of high-dose cyatarabine for acute myeloid leukemia. Blood 121, 26-28.

Marmann, A., Aly, A. H., Lin, W., Wang, B. and Proksch, P. (2014) Cocultivation - a powerful emerging tool for enhancing the chemical diversity of micororganisms. Mar. Drugs 12, 1043-1065.

Martins, A., Vieira, H., Gaspar, H. and Santos, S. (2014) Marketed marine natural products in the pharmaceutical and cosmeceutical industries: tips for success. Mar. Drugs 12, 1066-1101.

Maruzzo, M., Brunello, A., Diminutto, A., Rastrelli, M. and Basso, U. (2016) Long-term response to first-line trabectedin in an elderly female patient with a metastatic leiomyosarcoma unfit for anthracycline. Anticancer Drugs 27, 264-267.

Mayer, A. M., Glaser, K. B., Cuevas, C., Jacobs, R. S., Kem, W., Little, R. D., Mclntosh, J. M., Newman, D. J., Potts, B. C. and Shuster, D. E. (2010) The odyssee of marine pharmaceuticals: a current pipeline perspective. Trends Pharmacol. Sci. 31, 255-265.

Mayer, A. M. S. (2016) Marine pharmaceuticals: the clinical pipeline. [cited 2016 Aug 01] Available from: http://marinepharmacology. midwestern.edu/clinPipeline.htm/.

Mendola, D. (2000) Aquacultural production of bryostatin 1 and ecteinascidin 743. In Drugs from the Sea (N. Fusetani, Ed.), pp. 120-133. Karger, Basel.

Miljanich, G. P. (2004) Ziconotide: neuronal calcium channel blocker for treating severe chronic pain. Curr. Med. Chem. 11, 3029-3040.

Mocz, G. (2007) Fluorescent proteins and their use in marine biosciences, biotechnology, and proteomics. Mar. Biotechnol. 9, 305328.

Molinski, T. F., Dalisay, D. S., Lievens, S. L. and Saludes, J. P. (2009) Drug development from marine natural products. Nat. Rev. Drug Discov. 8, 69-85.

Morris, P. G. (2010) Advances in therapy: eribulin improves survival for metastatic breast cancer. Anticancer Drugs 21, 885-889.

Mullis, K. B. and Falcona, F. A. (1987) Specific synthesis of DNA in vitro via a polymerase-catalyzed chain-reaction. Meth. Enzymol. 155, 335-350.

Mutschler, E., Geisslinger, G., Menzel, S., Ruth, P. and Schmidtko, A. (2016) Pharmakologie kompakt: Allgemeine und Klinische Pharmakologie, Toxikologie. Wissenschaftliche Verlagsgesellschaft Stuttgart. German.

Newman, D. J. and Cragg, G. M. (2004) Marine natural products and related compounds in clinical and advanced preclinical trials. $J$. Nat. Prod. 67, 1216-1238.
Newman, D. J. and Cragg, G. M. (2014) Marine-sourced anti-cancer and cancer pain control agents in clinical and late preclinical development. Mar. Drugs 12, 255-278.

Newman, D. J. and Cragg, G. M. (2016) Drugs and drug candidates from marine sources: an assessment of the current "state of play". Planta Med. 82, 775-789

Olivera, B. M., Gray, W. R., Zeikus, R., Mclntosh, J. M., Varga, J., Rivier, J., DeSantos, V. and Cruz, L. J. (1985) Peptide neurotoxins from fish-hunting cone snails. Science 230, 1338-1343.

Pean, E., Klaar, S., Berglund, E. G., Salmonson, T., Borregaard, J., Hofland, K. F., Ersbøll, J., Abadie, E., Giuliani, R. and Pignatti, F. (2012) The European medicines agency review of eribulin for the treatment of patients with locally advanced or metastatic breast cancer: summary of the scientific assessment of the committee for medicinal products for human use. Clin. Cancer Res. 18, 44914497.

Pro, B., Advani, R., Brice, P., Bartlett, N. L., Rosenblatt, J. D., Illidge, T., Matous, J., Ramchandren, R., Fanale, M., Connors, J. M., Yang, Y., Sievers, E. L., Kennedy, D. A. and Shustov, A. (2012) Brentuximab vedotin (SGN-35) in patients with relapsed or refractory systemic anaplastic large-cell lymphoma: results of a phase II study. J. Clin. Oncol. 30, 2190-2196.

Proksch, P., Putz, A., Ortlepp, S., Kjer, J. and Bayer, M. (2010) Bioactive natural products from marine sponges and fungal endophytes. Phytochem. Rev. 9, 475-489.

Pérez-Victoria, I., Martin, J. and Reyes, F. (2016) Combined LC/UV/ MS and NMR strategies for the dereplication of marine natural products. Planta Med. 82, 857-871.

Radjasa, O. K., Vaske, Y. M., Navarro, G., Vervoort, H. C., Tenney, K., Linington, R. G. and Crews, P. (2011) Highlights of marine invertebrate-derived biosynthetic products: their biomedical potential and possible production by microbial associants. Bioorg. Med. Chem. 19, 6658-6674.

Ramasamy, M. S., Arumugam, P., Manikandan, S. and Murugan, A. (2011) Molecular and combinatorial array of therapeutic targets from conotoxins. Am. J. Drug Discovery Dev. 1, 49-57.

Sagar, S., Kaur, M. and Mineman, K. P. (2010) Antiviral lead compounds from marine sponges. Mar. Drugs 8, 2619-2638.

Schofield, M. M., Jain, S., Porat, D., Dick, G. J. and Sherman, D. H. (2015) Identification and analysis of the bacterial endosymbiont specialized for production of the chemotherapeutic natural product ET-743. Environ. Microbiol. 17, 3964-3975.

Schweder, T., Lindequist, U. and Lalk, M. (2005) Screening for new metabolites from marine microorganisms. In Advances in Biochemical Engineering/Biotechnology, Vol. 96: Marine Biotechnology (Y. LeGal and R. Ulber, Eds.), pp. 1-48. Springer, Berlin, Heidelberg.

Shimomura, O. (2009) Discovery of green fluorescent protein (GFP) (Nobel lecture). Angew. Chem. Int. Ed. Engl. 48, 5590-5602.

Skropeta, D. (2008) Deep-sea natural products. Nat. Prod. Rep. 25, $1131-1166$

Smith, J. A., Wilson, L., Azarenko, O., Zhu, X., Lewis, B. M., Littlefield, B. A. and Jordan, M. A. (2010) Eribulin binds at microtubule ends to a single site on tubulin to suppress dynamic instability. Biochemistry 49, 1331-1337.

Snelgrove, P. V. (2016) An ocean of discovery: biodiversity beyond the Census of Marine Life. Planta Med. 82, 790-799.

Suleria, H. A., Osborne, S., Masci, P. and Gobe, G. (2015) Marinebased nutraceuticals: an innovative trend in the food and supplement industries. Mar. Drugs 13, 6336-6351.

Sutherland, M. S., Sanderson, R. J., Gordon, K. A., Andreyka, J., Cerveny, C. G., Yu, C., Lewis, T. S., Meyer, D. L., Zabinski, R. F., Doronina, S. O., Senter, P. D., Law, C. L. and Wahl, A. F. (2006) Lysosomal trafficking and cysteine protease metabolism confer target-specific cytotoxicity by peptide-linked anti-CD30-auristatin conjugates. J. Biol. Chem. 281, 10540-10547.

Takeyama, H., Takeda, D., Yazawa, K., Yamada, A. and Matsunaga, T. (1997) Expression of the eicosapentaenoic acid synthesis gene cluster from Shewanella sp. in a transgenic marine cyanobacterium, Synechococcus sp. Microbiology 143, 2725-2731.

Tarman, K., Lindequist, U. and Mundt, S. (2013) Metabolites of marine microorganisms and their pharmacological activities. In Marine Microbiology: Bioactive Compounds and Biotechnological Applica- 
tions (S. K. Kim, Ed.), pp. 393-415. Wiley-VCH, Weinheim.

Terlau, H. and Olivera, B. M. (2004) Conus venoms: a rich source of novel ion channel-targeted peptides. Physiol. Rev. 84, 41-68.

Teuscher, E. and Lindequist, U. (2010) Biogene Gifte. Wissenschaftliche Verlagsgesellschaft, Stuttgart. German.

Thomas, N. V. and Kim, S. K. (2013) Beneficial effects of marine algal compounds in cosmeceuticals. Mar. Drugs 11, 146-164.

Weinheimer, A. J. and Spraggins, R. L. (1969) The occurrence of two new prostaglandin derivatives (15-epi-PGA2 and its acetate, methyl ester) in the gorgonian Plexaura homomalla chemistry of coelenterates. XV. Tetrahedron Lett. 10, 5185-5188.

Witte, A. V., Kerti, L., Hermannstädter, H. M., Fiebach, J. B., Schreiber, S. J., Schuchardt, J. P., Hahn, A. and Flöel, A. (2014) Long-chain omega- 3 fatty acids improve brain function and structure in older adults. Cereb. Cortex 24, 3059-3068.

World Register of Marine Species [Internet] WoRMS Editorial Board; 2016 [cited 2016 Aug 03]. Available from: http://www.marinespecies.org/.

Wu, C. H. (2009) Palytoxin: membrane mechanisms of action. Toxicon 54, 1183-1189

Younes, A., Gopal, A. K., Smith, S. E., Ansell, S. M., Rosenblatt, J. D. Savage, K. J., Ramchandren, R., Bartlett, N. L., Cheson, B. D., de Vos, S., Forero-Torres, A., Moskowitz, C. H., Connors, J. M. Engert, A., Larsen, E. K., Kennedy, D. A., Sievers, E. L. and Chen, R. (2012) Results of a pivotal phase II study of brentuximab vedotin for patients with relapsed or refractory Hodgkin's lymphoma. J. Clin. Oncol. 30, 2183-2189. 